\title{
Improvement of the gas chromatographic method for diagnosing developing defects in oil-filled electrical equipment based on the analysis of furan compounds
}

\author{
Ngoc Dan $\mathrm{Vu}^{1,{ }^{*}}$, Alina Vyacheslavovna Taneeva ${ }^{1}$, and Vyacheslav Fedorovich Novikov ${ }^{1}$ \\ ${ }^{1}$ Kazan state power engineering university, Kazan, Russia
}

\begin{abstract}
During the operation of oil-filled electrical equipment under the influence of temperature, humidity and other negative factors, the destruction of paper insulation occurs. As a result of this destruction, furan compounds are formed, which get into the transformer oil. To identify the process of destruction of paper insulation, control of furan compounds in transformer oil is carried out by instrumental methods. Of these methods, the most widely used is gas chromatography using packed chromatographic columns, on the basis of which guidelines have been developed. To improve gas chromatographic methods for monitoring furan compounds, we used a highly efficient quartz capillary column filled with a polar stationary phase based on polyethylene glycol. The sample was injected into the injector of the chromatograph Chromos-GC1000 using an automated dosing system with a vial for 23 samples. Used transformer oil of the GK-1 brand of Almetyevsk electrical networks was taken as the object of research; The optimal retention characteristics of standard sorbates were preliminary determined, which were used as organic extractants of transformer oil and furan compounds. The effect of temperature on the process of chromatographic analysis of furfuryl alcohol and organic extractants was determined, on the basis of which it was established that the selectivity of separation is determined by the nature of intermolecular interactions in the sorbate-sorbent system, in particular, the formation of a hydrogen bond. It has been shown that the selectivity coefficient for the separation of furfuryl alcohol depends on the physicochemical nature of organic extractants, their boiling points and dipole moments and has the highest values for the analyzed pair of components: furfuryl alcohol - ethanol.
\end{abstract}

\section{Introduction}

At present, control over the technical condition of oilfilled electrical equipment is carried out by instrumental methods. In power enterprises of the Russian Federation, this control is carried out by chromatographic methods, which are characterized by a sufficiently high sensitivity and accuracy and allow the determination of the products of its destruction in transformer oil. Chromatographic methods for controlling transformer electrical equipment are included in the main regulatory documents that determine the main provisions of diagnostics.

During the operation of power transformers, gaseous substances are concentrated in them, which are products of the destruction of transformer oil. Therefore, usually the diagnosis of slowly developing defects in transformer electrical equipment is carried out by analyzing gases dissolved in transformer oil [1-4].

During the operation of oil-filled electrical equipment, as a result of the destruction of paper insulation due to thermal oxidative and hydrolytic transformation of cellulose, furan compounds are formed. To control these contents in transformer oil, chromatographic analysis methods are used. For the extraction of furan compounds from transformer oil, it is more promising to use aliphatic alcohols with higher boiling points, which contain less water. To control the degree of destruction of solid insulation, the use of furfuryl alcohol is more promising [5-6].

To determine furfuryl alcohol in transformer oil, we used transformer oil sorption by various instrumental methods. For this purpose, the process of adsorption, obtaining chemical derivatives and extraction is used, which is subdivided into liquid, gas, solid-phase, supercritical fluid, as well as using low temperatures [79]. In addition, a promising direction is extraction in microwave, magnetic, electromagnetic and centrifugal fields, which makes it possible to separate the components of transformer oil into groups of substances. In this case, the process of sorption of transformer oil can be easily automated, which will lead to a decrease in the error in determining the analyzed components by eliminating the influence of the human factor [10-12].

\section{Materials and methods}

To process the results of chromatographic analysis, a computer program for the collection, storage and

\footnotetext{
* Corresponding author: vndan@cnd.edu.vn
} 
processing of chromatographic information "Chromos 2.24" was used with the possibility of printing the obtained experimental data on a printer. The chromatographic columns used were a capillary column $30 \mathrm{~m}$ long, $0,32 \mathrm{~mm}$ inner diameter, filled with a stationary phase based on polyethylene glycol "Vako BoHa VB WAX P / n CF 5903032050A", with a film thickness of $0,5 \mu \mathrm{m}$. The analytes were dosed into an injector of a gas-liquid chromatograph using an automatic liquid dispenser "ALD-23", with vials for 23 samples. The volume of the sample introduced into the chromatograph evaporator in all cases did not exceed 1,0 $\mu \mathrm{l}$. The rate of sample collection into vials was $20 \mu \mathrm{l} / \mathrm{sec}$, the rate of dosing was $30 \mu \mathrm{l} / \mathrm{sec}$, and the time of sample accumulation in the evaporator of the chromatograph during dispensing was $10 \mathrm{sec}$. Chromatographic analysis was carried out both in isothermal mode and with linear programming of the temperature of the chromatographic column from $40^{\circ} \mathrm{C}$ to $250^{\circ} \mathrm{C}$ with a temperature rise rate from five to ten degrees per minute. The evaporator temperature was $200^{\circ} \mathrm{C}$, the detector temperature was $240^{\circ} \mathrm{C}$. Argon was used as a carrier gas. The hydrogen velocity was $25 \mathrm{~cm}^{3} / \mathrm{min}$, the air velocity was 250 $\mathrm{cm}^{3} / \mathrm{min}$.

\section{Discussion result}

Recently, for the analysis of complex organic mixtures, capillary gas-liquid chromatography has become widely used, which is more efficient, since it allows one to obtain narrower peaks. With the user of capillary columns, it is possible to carry out analysis in a wider range of boiling points of the analyzed components, since they do not contain sorption in the grains of a solid carrier, which exists in packed columns. To assess the chromatographic properties of organic solvents and furfuryl alcohol, we determined their absolute retention times on a capillary column at different temperatures and numerical values.

In figures 1 show chromatograms of separation of organic solvents and furfuryl alcohol, which is a marker for diagnostics of oil-filled electrical equipment, since it migrates into transformer oil as a result of destruction of paper insulation.

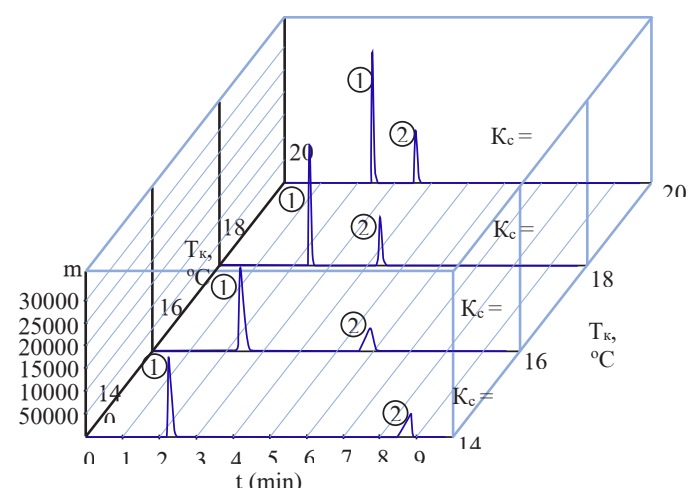

Fig. 1. Chromatogram of the separation of Ethyl acetate and Furfuryl alcohol at different temperatures of analysis in the coordinates: Response of the detector signal, $\mathrm{mV}$; Tk - analysis temperature, ${ }^{\circ} \mathrm{C}$. 1. Ethyl acetate, 2. Furfuryl alcohol.
As can be seen from the figures, in all cases there is a significant decrease in the retention time of all organic solvents with an increase in temperature in the range from 140 to $200^{\circ} \mathrm{C}$. At the same time, at low temperatures of analysis, the peak of furfuryl alcohol turns out to be blurred, which is determined by its rather high boiling point. With an increase in the analysis temperature, the chromatographic peak of furfuryl alcohol becomes more symmetric. In this case, the selectivity of the separation of organic solvents and furfuryl alcohol also depends on temperature.

To assess the mechanism of chromatographic separation of organic solvents in gas-liquid chromatography, the relative retention characteristics are widely used, which are associated by a logarithmic dependence with the physicochemical properties of sorbents and stationary liquid phases. We used the retention time as a relative characteristic of the retention of organic solvents.

Table 1. Absolute dependence of the retention time of aliphatic alcohols and furfuryl alcohol on the temperature of the chromatographic column.

\begin{tabular}{|c|c|c|c|c|c|}
\hline \multirow{2}{*}{$\begin{array}{c}\mathrm{T}_{\mathrm{K}} \\
{ }^{\circ} \mathrm{C}\end{array}$} & \multicolumn{5}{|c|}{ Retention time of aliphatic alcohols at temperature $\left(\mathrm{t}_{\mathrm{R}}, \mathrm{min}\right)$} \\
\cline { 2 - 6 } & Methanol & Ethanol & $\begin{array}{c}\mathrm{n}- \\
\text { Butanol }\end{array}$ & $\begin{array}{c}\text { iso- } \\
\text { Aminol }\end{array}$ & $\begin{array}{c}\text { Furfuryl } \\
\text { alcohol }\end{array}$ \\
\hline 40 & 5.21 & 6.17 & 24.55 & 39.81 & - \\
\hline 60 & 3.47 & 3.91 & 12.08 & 15.67 & - \\
\hline 80 & 2.75 & 2.90 & 6.68 & 7.94 & 90.99 \\
\hline 100 & 2.45 & 2.46 & 3.89 & 4.74 & 35.89 \\
\hline 120 & 2.34 & 2.43 & 2.95 & 3.31 & 16.60 \\
\hline 140 & 2.27 & 2.38 & 2.69 & 2.95 & 8.82 \\
\hline 160 & 2.29 & 2.39 & 2.60 & 2.73 & 5.81 \\
\hline 180 & 2.34 & 2.43 & 2.57 & 2.67 & 4.40 \\
\hline 200 & 2.40 & 2.53 & 2.57 & 2.71 & 3.73 \\
\hline
\end{tabular}

In fig. 2. shows the dependence of the logarithm of the retention time of aliphatic alcohols of furfuryl alcohol on the temperature of the analysis

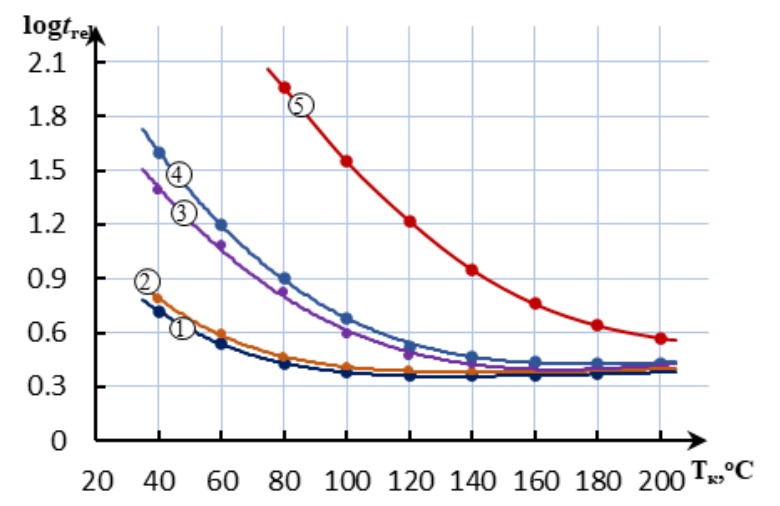

Fig. 2. Dependence of the logarithm of the retention time of aliphatic alcohols and furfuryl alcohol on the analysis temperature: 1. Methanol; 2. Ethanol; 3. n-Butanol; 4. iso.Aminol; 5. Furfuryl alcohol.

As seen from fig. with an increased separation temperature, the logarithm of the retention time of aliphatic alcohols and furfuryl alcohol significantly decreases. This is obviously associated with the formation of an intermolecular hydrogen bond of the hydroxy group of the alcohol with the structural 
fragments of the polar stationary phase. Since the energy of the intermolecular hydrogen bond decreases with increasing temperature, the retention time of aliphatic alcohols and furfuryl alcohol decreases.

At a temperature exceeding $120^{\circ} \mathrm{C}$, all aliphatic alcohols practically do not separate and their retention time does not depend on the temperature of the chromatographic column. This indicates a change in the chromatographic separation mechanism, when at an elevated temperature intermolecular hydrogen bonds are not formed in the sorbate-sorbent system, and the separation proceeds according to the dispersion mechanism, i.e. the stationary phase in the capillary column becomes non-polar. It is known that the extraction process of transformer oil can also be affected by various impurities contained in the organic extractant. For this purpose, organic solvents were analyzed for the content of associated impurities.

To determine furfuryl alcohol directly in the used transformer oil, a series of experiments was carried out. For this purpose, a direct analysis of transformer oil was carried out without preliminary sample preparation. For this purpose, furfuryl alcohol in an amount of $0,5 \%$ by weight and carbon tetrachloride were added to fresh transformer oil. The sample was injected directly into an injector of a gas-liquid chromatograph.

In fig. 3 (A) shows a chromatogram of the separation of used transformer oil from which it can be seen that furfuryl alcohol elutes in the form of a symmetrical peak against the background of a significant deviation from the baseline. This is obviously due to the fact that the used transformer oil contains asphaltenes and resins that have high boiling points, are characterized by high viscosity and, therefore, are washed out of the chromatographic column with great difficulty by an inert carrier gas. The chromatographic column is contaminated with high-boiling components of transformer oil; therefore, to clean it, it is necessary to carry out regular conditioning at an elevated temperature.
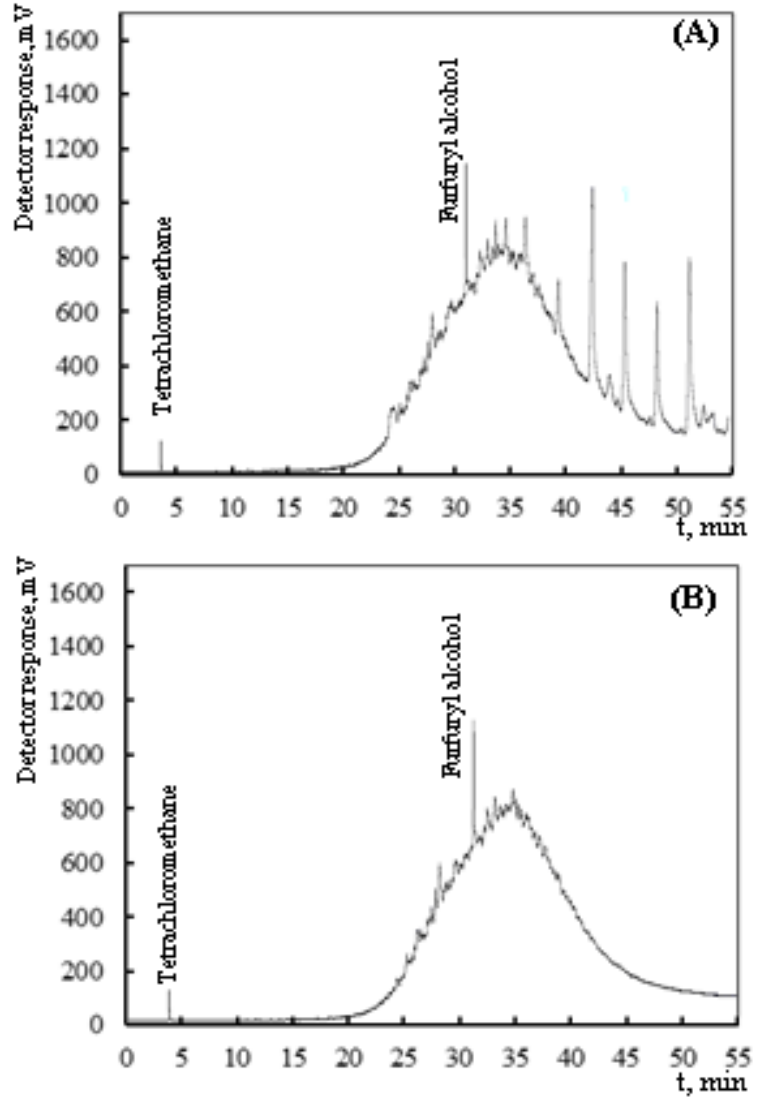

Fig. 3. Chromatogram of the separation of individual components of used transformer oil and furfuryl alcohol. The eluent is carbon tetrachloride. A. Used transformer oil; B. Transformer oil purified by sorption of the zeolite-containing rock of the Tatarsko-Shatrashanovskoye field.

As seen from fig. 3 (A), the transformer oil also contains peaks of higher boiling point components that are not identified.

To purify transformer oil from accompanying impurities, we used the adsorption method using zeolitecontaining rocks of the Tatarsko-Shatrashanovskoye field. For this purpose, the spent transformer oil was passed through an adsorption chromatographic column filled with a zeolite-containing rock.

As seen from fig. 3 (B), the transformer oil is purified from accompanying impurities, since the "tail" of the peak lacks the components that make up the transformer oil. In this case, the analysis time of furfuryl alcohol does not exceed 30 minutes.

\section{Findings}

Based on the studies carried out, it has been shown that used transformer oil can be analyzed using gas-liquid chromatography, with which it is possible to determine their composition. Furfuryl alcohol resulting from degradation of paper insulation can be monitored by direct analysis on a capillary column with a polar stationary liquid phase. 


\section{References}

1. V.F. Novikov, E.YU. Abdullazyanova, E.V. SHamsutdinov (pod obshch. red.), Diagnostika maslonapolnennogo elektrooborudovaniya hromatograficheskimi metodami, Novye tekhnologii, materiala i oborudovaniya (V 3 t., Kazan', Kazan. Gos. Energ. un-t, V. 3, 138-160, 2018)

2 S. Singh, M. Bandyopadhyay, Dissolved gas analysis technique for incipient fault diagnosis in power transformers: a bibliographic survey, IEEE Electrical Insulation Magazine, 26 (6), 41-46 (2010)

3. E. Yokenbah, H. Borsi, Condition and diagnosis of power transformers, Jnternational conference on condition monitoring and diagnostic, 21-24 (2008)

4. V.F. Novikov, A.A. Kartashova, A.V. Taneeva, Instrumental'nye metody analiza, $\mathrm{V}$ trekh chastyah, CH. III, Gazohromatograficheskij kontrol' proizvodstvennyh processov V energetike: Monografiya (Kazan': Kazan. gos. energ. un-t, 328, 2018)

5. A.A. Kartashova, V.F. Novikov, Opredelenie furanovyh soedinenij $\mathrm{v}$ transformatornom masle gazohromatograficheskim metodom $\mathrm{s}$ ispol'zovaniem novyh sorbentov, Izvestiya vysshih uchebnyh zavedenij, Problemy energetiki, 1-2, 47-52 (2016)

6. V.F. Novikov, A.V. Taneeva, Kontrol' tekhnicheskogo sostoyaniya silovyh transformatorov: Praktikum (Kazan': Kazan. gos. energ. un-t, 43, 2018)

7. A.L.B. Dias, G.N. Cunha, P. Santos, M.A.A. Meireles, J. Martinez, Fusel oil: Water adsorption and enzymatic synthesis of acetate esters in supercritical CO2, The Journal of Supercritical Fluids, 142, 22-31 (2018)

8. A.L.B. Dias, P. Santos, J. Martinez, Supercritical $\mathrm{CO} 2$ technology applied to the production of flavor ester compounds through lipase-catalyzed reaction: a review, Journal of $\mathrm{CO} 2$ Utilization, 23, 159-178 (2018)

9. P. Santos, M.A.A. Meireles, J. Martinez, Production of isoamyl acetate by enzymatic reactions in batch and packed bed reactors with supercritical CO2, The Journal of Supercritical Fluids, 127, 71-80 (2017)

10. N. Montoya, J. Duran, F. Cordoba, I. Gil, C. Trujillo, G. Rodriguez, Colombian fusel oil El aceite de fusel de Colombia, Ingenieria e Investigacion, 36, 21-27 (2016)

11. P. Santos, C.A. Rezende, J. Martinez, Activity of immobilized lipase from Candida antarctica (Lipozyme 435) and its performance on the esterification of oleic acid in supercritical carbon dioxide, The Journal of Supercritical Fluids, 107, 170-178 (2016)
12. P. Santos, G.L. Zabot, M.A.A. Meireles, M.A. Mazutti, J. Martínez, Synthesis of Eugenyl Acetate by Enzymatic Reactions in Supercritical Carbon Dioxide, Biochemical Engineering Journal, 114, 1-9 (2016)

13. A. Mecke, I. Lee, J.R. Baker jr., M.M. Banaszak Holl, B.G. Orr, Eur. Phys. J. E, 14, 7 (2004). 